Taheri, B., Jafari, A., \& Okumus, B. (Forthcoming). Ceremonious politeness in consuming food in VFR tourism: Scale development, The Service Industries Journal.

\title{
Ceremonious politeness in consuming food in VFR tourism: Scale development
}

\section{在VFR旅游中消费食物的正式礼仪礼貌：规模发展}

\begin{abstract}
摘要

Understanding the desire for visiting friends and relatives (VFR) has been examined in previous studies. Yet, research on the antecedences and consequences of social interaction between host and guest in VFR tourism has not received enough attention. Addressing this gap, this study introduces ceremonious politeness (CP) by tourists in consuming food as a cultural code that facilitates the establishment of a communally arranged form of social interaction. Using a mixed methods scale-development approach (e.g., Delphi technique, qualitative interviews, and surveys) during fourteen months in 2015-2016, it develops and validates a CP scale to measure the impact of self-accountability and perceived others' control on tourists' sense of self-blame in social interaction situation related to consuming food in VFR tourism. The study contributes to the body of knowledge by introducing the concept of $\mathrm{CP}$ in a non-commercial setting.
\end{abstract}

在以前的研究中已经了解走亲访友的愿望 (VFR)。然而, 对VFR旅游中主人与客人 之间社会互动的前因和后果的研究尚未得到足够重视。针对这个空白, 本文引入了正 式的的礼仪礼貌 ( CP ) 作为游客消费食品中促进建立社会互动形式的一种文化规范. 在2015-

2016年的十四个月内, 本研究采用混合的尺度发展方法 ( 如德尔菲技术, 定性访谈和 调查 ), 开发和验证了一个 CP的尺度来衡量在VFR旅游中消费食物的情况中的自我问 责和感知他人的控制对游客的社会互动的影响.

该研究通过在非商业环境中引入 $\mathrm{CP}$ 的概念来促进知识体系。

Keywords: VFR, ceremonious politeness, scale development

全键词: 走亲访友, 正式的的礼仪礼貌, 规模发展 


\section{Introduction}

Over the past decade, Visiting Friends and Relatives (VFR) tourism has witnessed the rise of a nuanced stream of research that embeds tourism within the broad arena of social life. This scholarship conceptualizes the VFR tourist as a social being who visits significant others, fulfils various obligations, stays at their home, and generally uses tourism to connect with their loved ones through the "thick, embodied socialities of corporeal proximity" (Larsen, Urry, \& Axhausen, 2007, p. 247). Highlighting the complexities of the 'home' and 'away' experiences, researchers (Larsen et al., 2007; Shani, 2013; Shani \& Uriely, 2012; Uriely, 2010) critique the traditional conceptions (e.g., Cohen, 1979; Smith, 1978) of tourism as solely an escape from everyday life (e.g., home, friends and relatives) into the realm of the extraordinary. Larsen et al. (2007) and Shani (2013) also question the prevailing theorization (e.g., Asiedu, 2008; Backer, 2012; Paci, 1994) of VFR tourism as a market phenomenon narrowly measured against its economic value (e.g., tourist expenditure). Hence, with a focus on sociality as the 'linking value' (Cova, 1997) of VFR, scholars analyze tourism within everyday life situations where, in the interest of sociality, guests and hosts compromise certain aspects of their daily life rituals (Larsen et al., 2007; Shani, 2013; Shani \& Uriely, 2012; Uriely, 2010).

This stream of research argues that VFR inserts both positive and negative impacts on guests and hosts. On the one hand, VFR helps people strengthen their social bonds, enjoy sightseeing, travel at affordable costs, and achieve psychological wellbeing and happiness (Larsen et al., 2007; Shani, 2013; Shani \& Uriely, 2012; Uriely, 2010). On the other hand, it imposes certain difficulties on the parties involved. For example, while both guests and hosts may encounter situational loss of privacy, control, and behavioral constraints (Larsen et al., 2007; Shani, 2013), hosts may additionally experience psychological stress, financial pressure, and physical hardship (Shani \& Uriely, 2012). These valuable developments have significantly enhanced the understanding of the socio-psychological dynamics that both influence and are influenced by VFR tourism. However, there is still more to learn about how cultural norms may influence the behaviors of, and interactions between, hosts and guests in different societies.

The present study suggests that a contextual analysis of VFR will further the understanding of the performativity of situational behaviors in the host-guest interactions. Since socio-psychological phenomena do not occur in a cultural vacuum, it is important to understand how cultural specificities may influence socio-psychological dimensions of VFR tourism. Addressing such a gap, this study examines the concept of ceremonious politeness (CP) (i.e., showing good manners to please others), as a cultural code of conduct, in social interaction situation such as eating at home. From a Goffman (1959) perspective, CP facilitates the establishment of a mutually agreed upon form of social interaction. This article demonstrates that in order to conform to the culturally defined rituals of hospitality (i.e., hosts' generous treatment of guests and guests' gratitude toward hosts) (see Aramberri, 2001), guests may encounter a sense of self-blame (i.e., negative consequences) for compromising their dietary behavior and overeating (i.e., individuals feel obliged to behave in certain ways).

Koc (2013) states that in commercial settings (e.g., hotels and restaurants) tourists may slip into the conditions of overeating and subsequently encounter a sense of self-blame, which results from their loss of self-control and hedonic submission to the staged conditions of holidaying. Koc further notes that apart from external factors (e.g., food quality, quantity, and variety), personal attributes such as the inability to preserve self-control against external stimuli (e.g., the abundance of food) influence tourists' overall experiences. The present study both complements and extends Koc's study into the VFR context. Using attribution and 
blame (Calder \& Burnkrant, 1977; Shaver \& Drown, 1986) theories, this research aims to develop and validate a new scale to measure the CP of tourists social interaction in situations, particularly when consuming food in VFR tourism, and establish its value in defining, predicting, and understanding social interaction when guest receives services such as food from hosts in VFR tourism. As this is one of the first studies in the tourism field, it contributes to the body of knowledge by presenting a systematic process of scaledevelopment in VFR tourism research via various techniques. The study also contributes to the VFR tourism literature by scrutinizing how, as a cultural code of conduct, CP mediates the social interaction between the gust and the host.

\section{Ceremonious politeness $(\mathrm{CP})$}

Ceremonious politeness (CP) refers to a broad set of courteous actions of displaying good manners towards pleasing and comforting others (Kerbrat-Orecchioni, 2012; Taussig, 2002). $\mathrm{CP}$ is not uniform. It is rather a socially constructed concept, which is identified with etiquette and has diverse forms, rituals, and applications in different societies (KerbratOrecchioni, 2012; Pan \& Kádár, 2011). It encompasses a wide range of linguistic (e.g., act of speech in compliments) and non-linguistic (e.g., behavioral) elements that can signify people's perceptions about their interpersonal relationships and the construal of their social environment (Ambady, Koo, Lee, \& Rosenthal, 1996). From a Goffmanian lens (1959), CP acts as a catalyst to establish social interaction. Depending on a variety of criteria, such as percept of social (power) distance, formality of the social interaction situation, and the degree of imposition on others, people may display different forms and degrees of CP (Ambady et al., 1996; Kerbrat-Orecchioni, 2012). For example, in situations where perceived others' control is high, individuals tend to show a higher level of politeness towards their addressees (Spencer-Oatey, 2005).

It is not necessarily a genuine act of expressing one's true intentions, attitudes, or feelings. Rather, it can be a strategy individuals use to achieve certain objectives, such as maintaining good relationships with people (Pinto, 2011). For example, in order to please others, people may say or do something against their own self-standards or will. By and large, $\mathrm{CP}$ acts as a social etiquette upon which people's day-to-day interactions are organized (Leech, 2005). There may be variations in CP manifestations (e.g., apologies, offers, requests, and compliments) (Leech, 2005, p. 1). In line with this, Azadarmaki and Bikaran-Behesht (2010) discuss the paradoxical nature of CP. On one hand, it signifies respect for others and, hence, can help strengthen interpersonal relationships. On the other hand, it can bring negative consequences for individuals. For example, in a service encounter like a dining situation, the host may feel duty-bound to insist that their guest should eat more food. If, upon the host's persistence, the guest eats more food, this signifies the guest's appreciation for hospitality. If the guest is able to eat more food, both the guest and host would feel appreciated in their interpersonal relationship. However, if the guest eats only to please the host, (s)he may find herself/himself in an uncomfortable situation of imposition. As such, since rejecting the host's offer may signify ingratitude toward the host, to avoid feelings of guilt (for breaking the rules of hospitality), the guest feels obliged to submit to the host's will at the expense of her/his own self-control. As such, this study attempts to explore the CP concept by conducting a comprehensive analysis of guest's behavior toward their appreciation for the host's hospitality, and also by developing a measure of CP for the first time following a multi-staged procedure (DeVellis, 2003; Michel, Tews, \& Kavanagh, 2014).

\section{$\mathrm{CP}$ and related concepts}

Attribution theory suggests that "behavior is attributed to internal, personal causes or to external forces" (Calder \& Burnkrant, 1977, p. 29). Individuals' personal features (e.g., 
feelings or experiences) and others' behaviors in a social environment influence their subsequent behaviors and attitudes. Due to such interconnectivity, people may rely on causal explanations in order to make sense of their environment (e.g., their hosts' home), personal contacts (e.g., host), or a particular event (e.g., hospitality), in order to explain and justify their actions, people attribute their behaviors to internal or external causes. Causal explanations can help researchers better understand 'how' and 'why' individuals act in certain ways (Heider, 1958).

Pertinent to this study, responsibility, blame, and cause are three main types of attribution that involve the way in which guests use their behavior to explain incidents, events, or particular outcomes in their lives (Belk, Painter, \& Semenik, 1981; Heider, 1958). According to the theory of blame (Shaver \& Drown, 1986), responsibility is the state of accepting the duty of dealing with something. Failure to fulfil the duty results in a wrongdoing that is regarded as irresponsible and, hence, blameworthy. On the other hand, cause is what gives rise to a phenomenon. In daily life situations, individuals may assign the blame to different agents for causing the occurrence of misconduct or an undesirable consequence. Thus, this study adapts the VFR perspective by drawing on attribution theory and the theory of blame to identify the role of $\mathrm{CP}$ as being crucial for social interaction between the host and guest. This leads to hypothesizing the relationship between antecedents (i.e., self-accountability and perceived others' control) and consequences (i.e., self-blame) of $\mathrm{CP}$. The relationship between $\mathrm{CP}$ and related constructs will be assessed as part of establishing CP's predictive validity (Hair, Black, Babin \& Anderson, 2010).

Self-accountability holds oneself responsible for following their principles and facing the potential consequences of such principles (Passyn \& Sujan, 2006). It can even make people undergo hardship for certain purposes, such as maintaining relationships with their significant others (e.g., friends and relatives) (Passyn \& Sujan, 2006, 2012). Also, as social entities, people often develop a sense of perceived others' control; this means that individuals' behaviors can be influenced by the degree to which they submit to others' control (Kunzmann, Little, \& Smith, 2002). As the literature suggests, in situations wherein perceived self-accountability and others' control are high, individuals tend to show a higher level of CP (see also Spencer-Oatey, 2005). On the basis of the above theoretical arguments, it is proposed:

H1. Self-accountability positively affects $\mathrm{CP}$ while visiting friends and relatives.

H2. Perceived other's control positively affects $\mathrm{CP}$ while visiting friends and relatives.

According to Janoff-Bulman (1979), there are two types of self-blame: behavioral and characterological. While the former means blaming one's behavior for a particular negative incident, the latter refers to blaming one's character for repeating a regretful behavior. Under certain conditions such as $\mathrm{CP}$, individuals may behave in ways that yield blameworthy outcomes (Heider, 1958). To contextualize, to please others, one may go against her/his principle of moderate eating and encounter self-blame (i.e., negative consequences) for obligation to behave in ways. Therefore:

H3. CP relates positively to characterological self-blame while visiting friends and relatives.

H4. CP relates positively to behavioral self-blame while visiting friends and relatives.

Previous research on consumer decision-making processes asserts that high selfaccountability enhances the arousal of feelings of guilt, regret, and blame in individuals 
(Jayaratne, Sullivan Mort, \& Clare, 2015; Passyn \& Sujan, 2006; Peloza, White, \& Shang, 2013). That is those who account themselves for the occurrence of an undesirable action or outcome are more likely to experience guilt, regret or self-blame. Other studies (Reb \& Connolly, 2010) confirm that through situational actions (e.g., CP), self-accountability positively affects the emergence of self-blame. Therefore, it is anticipated that those who hold themselves accountable for pleasing their hosts, and hence exercise CP, are more likely to encounter self-blame (both characterological and behavioral) in social interaction situation while visiting friends and relatives and consuming food offered by them. Thus:

H5. Self-accountability has a positive relationship, (a) directly and (b) indirectly through CP, with characterological self-blame while visiting friends and relatives.

H6. Self-accountability has a positive relationship, (a) directly and (b) indirectly through CP, with behavioral self-blame while visiting friends and relatives.

In a similar vein, prior work (Peloza et al., 2013; Theotokis \& Manganari, 2014) confirms that those who firmly adhere to their self-standards are less likely to encounter a sense of guilt or self-blame when facing a dilemma. They are in control of their actions and have a low-level of perceived others' control. Following the same logic, it was predicted that those who have a high-level of perceived others' control encounter self-blame through the mediating role of $\mathrm{CP}$ in social interaction situation while visiting friends and relatives and consuming food offered by them. Thus, the following hypotheses are proposed:

H7. Perceived other's control has a positive relationship, (a) directly and (b) indirectly through $\mathrm{CP}$, with characterological self-blame while visiting friends and relatives.

H8. Perceived other's control has a positive relationship, (a) directly and (b) indirectly through $\mathrm{CP}$, with behavioral self-blame while visiting friends and relatives.

Figure 1 provides a graphical representation of the main hypotheses proposed in this study.

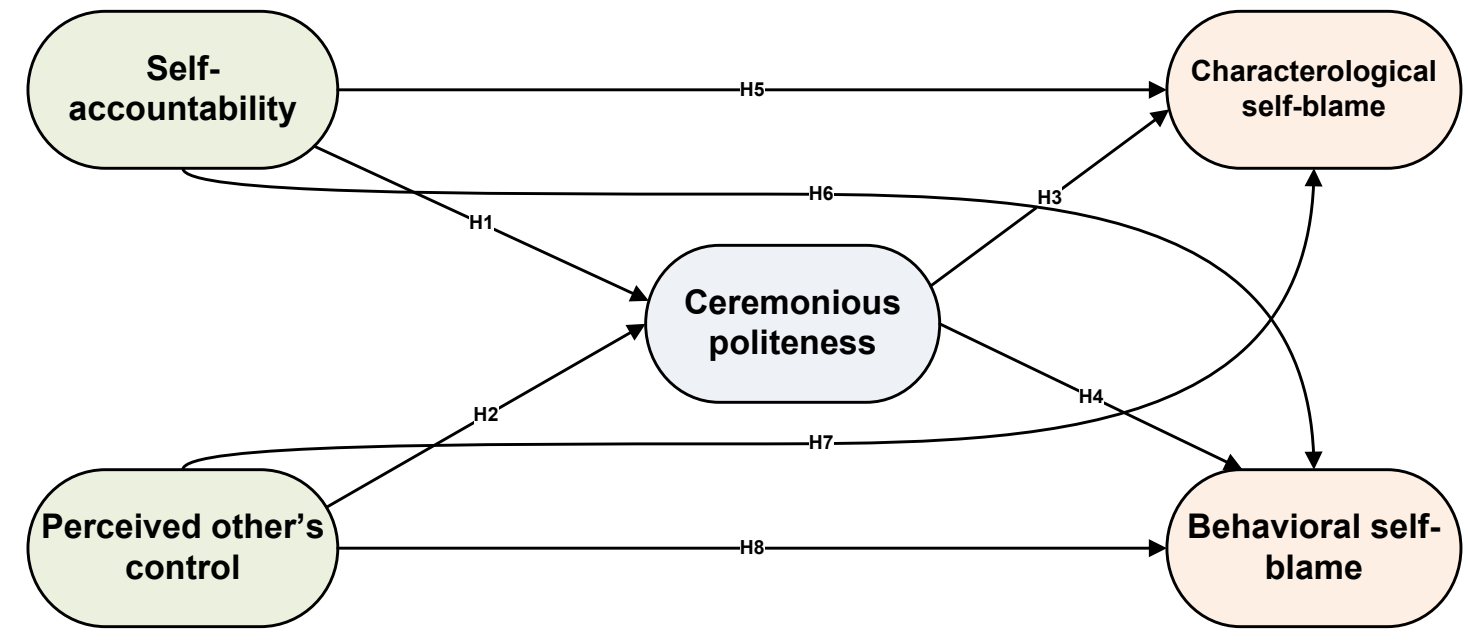

Figure 1. Main hypotheses proposed model.

\section{Methods and scale development}


To extend previous research on VFR tourism and to develop a CP scale, a sequential, mixed methods approach (Teddlie \& Tashakkori, 2009) was adopted. Following DeVellis (2003) and Churchill (1979), the scale development process involved five phases: (1) item generation; (2) construct formation; (3) initial purification; (4) construct validation; and (5) construct replication. Figure 2 summarizes the scale development procedures followed for this current study.

\begin{tabular}{|c|c|c|c|}
\hline $\begin{array}{c}\text { Phases 1\&2: } \\
\text { Item generation \& construct } \\
\text { formation }\end{array}$ & $\begin{array}{c}\text { Phase 3: } \\
\text { Items' purification } \\
\end{array}$ & \begin{tabular}{|c|} 
Phase 4: \\
Initial validation \& application of \\
the CP
\end{tabular} & $\begin{array}{c}\text { Phase 5: } \\
\text { Replication in other country } \\
\end{array}$ \\
\hline \begin{tabular}{|} 
+Study1-Interview $(\mathbf{n}=\mathbf{2 3}):$ \\
- Female and male; $18-70$ \\
years of age; diverse \\
cultural background \\
-Pool of 16 items was \\
generated \\
\\
+Study 2- Delphi ( $\mathbf{n}=\mathbf{2 0}$ ): \\
- international expert judges \\
-Readability check \\
-Final item pool of 8 items
\end{tabular} & $\begin{array}{c}\text { +Study 3- Survey }(\mathbf{n = 2 1 0 )} \\
\text { - University students using } \\
\text { UK representative sample } \\
\text { - Principal component } \\
\text { analysis } \\
\text { - Reliability analysis } \\
\text {-Correlation matrix } \\
\text { - Multicollinearity }\end{array}$ & $\begin{array}{c}\text { +Study 4- Survey ( } \mathbf{n}=673 \text { ) } \\
\text { - Visitors using Iranian } \\
\text { representative sample } \\
\text { - Pilot test ( } n=50) \\
\text {-Back-translation approach } \\
\text {-Assess CMV } \\
\text { - Assess confirmatory factor } \\
\text { analysis } \\
\text { - Assess normality } \\
\text { - Assess validity and reliability } \\
\text { of constructs } \\
\text { - Assess predictive relevance } \\
\text { - Assess fit indexes } \\
\text {-Assess invariance test } \\
\text { - Assess post-hoc analysis of } \\
\text { the indirect effects }\end{array}$ & $\begin{array}{c}\text { +Study 5- Survey (n=418) } \\
\text { - Visitors using Chinese } \\
\text { representative sample } \\
\text {-Back-translation approach } \\
\text {-Assess CMV } \\
\text { - Assess confirmatory factor } \\
\text { analysis } \\
\text { - Assess validity and reliability } \\
\text { of constructs } \\
\text { - Assess predictive relevance } \\
\text { - Assess fit indexes } \\
\text { - Assess post-hoc analysis of } \\
\text { the indirect effects }\end{array}$ \\
\hline
\end{tabular}

Figure 2. Scale development process

\section{Phases 1 and 2: Item generation and construct formation}

Using snowball sampling via four lead participants, 23 individuals were interviewed in phase 1. The interviews were conducted in different locations based on the participants' own preference. To explore whether the statements or items could entirely capture the CP scale's domain of content, a mixture of female and male guests between 18 and 70 years of age from diverse cultures were interviewed. The interviews started with general questions such as 'do you normally stay with your friends and relatives when your travel?' or 'what do you do when you stay with your friends and relatives?' These general questions led to more in-depth conversations, which gave rise to the participants' interesting stories about their social interaction with their friends and relatives during their stay (Jafari, Taheri, \& vom Lehn, 2013). Participants were encouraged to explain their stories with reference to examples. Following the thematic analysis of the qualitative data (Boyatzis, 1998), an initial pool of sixteen items as key components of CP was generated.

In the second step, to ensure face and content validity of these items, the Delphi technique was employed. As Miller (2001, p. 353) suggests, in the absence of "perfect knowledge", the Delphi technique can help researchers "generate opinion and move towards consensus on any issue that requires the input of ... disperse experts". Therefore, following the principles of member checking (DeVellis, 2003), using judgmental sampling, a panel of 20 independent, international judges (business school academics and $\mathrm{PhD}$ students) were consulted with regards to the sixteen items in phase 1.

Each panelist was asked to scrutinize the relevance, representativeness, clarity, test format, and wording. Round 1 started with an open-ended questionnaire. The quantitative items were complemented by the panelists' qualitative comments. In round 2, each panelist was given the second Delphi questionnaire and was requested to review the items shortened by researchers about the information gathered in round 1. The panel rating method for each item was followed in four categories: a) very representative; b) moderately representative; c) very little representative; and d) not at all representative. The majority of the items were rated as 'very representative' $(80 \%)$, some of the panel members indicated 'moderately representative' $(15 \%)$, and the rest indicated 'very little representative' $(5 \%)$. Based on their 
feedback, some statements were dismissed and other items were slightly refined. In the final round, the panel members were asked to check the selected items for the last time. All judges agreed that the final items accurately defined the level of $\mathrm{CP}$, which also confirms the indicator specification (Rossiter, 2002). This expert consensus endorsed the content validity and credibility of the interpretations. Therefore, eight items were considered as representative of the CP construct.

\section{Phase 3: Items' purification}

210 university students in the UK were used to test scale purification (Fetscherin \& Stephano, 2016). These national and international students (from 12 different cultural backgrounds) were registered in seven classes across dissimilar academic topics. The respondents consisted of $46 \%$ male and $54 \%$ female. These students were asked to assess their level of agreement with the items when they are traveling to their friends and relatives house and receiving any services from their guests (e.g., an eating) situation by indicating on a 7-point Likert-scale, with 1 indicating strongly disagree and 7 strongly agree.

\section{Phase 4: Initial validation and application of the CP}

Although the items relating to the $\mathrm{CP}$ construct were validated in the PCA in phase 3, little evidence of convergent, discriminate, and predictive validity was presented. In doing so, confirmatory phase 4 was conducted to establish the measurement items obtained from the phase 3. Data were collected in Tehran and Tabriz, two of Iran's most populated cities. Using convenience sampling, the participants were asked to answer the questionnaire based on their previous experience of travelling to a domestic destination and staying with relatives or friends. There was also a pilot test with 50 participants over a period of 14 days. The questionnaire was translated into Persian. A back-translation approach was employed to confirm the meaning of the question and its related categories. Informants were told that their answers would remain anonymous. This contributed to the minimization of social desirability bias and helped to reflect respondents' true feelings. The independent and dependent scales were placed in different parts of the survey (Podsakoff, MacKenzie, Lee, \& Podsakoff, 2003). Harman's one factor was used to test the presence of Common Method Variance (CMV). The eigenvalue PCA detected eight factors, and the highest portion of variance described by one factor was $23.71 \%$. Thus, CMV is not a concern for this study.

Data cleaning condensed the sample to 673 final questionnaires. Of the participants, $6 \%$ of them were 56 years old or above, $14.1 \%$ were between $46-55$ years old, $24.7 \%$ were between $36-45$ years old, $30.3 \%$ were between $26-35$, and $25 \%$ were $18-25$ years old. In relation to gender, $50.7 \%$ of the respondents were female and $49.3 \%$ were male. More than half of the participants $(59.9 \%)$ had basic education or had finished high school, and the rest held a university degree. All multi-item, reflective scales used in this study were adapted from previous scales including Kunzmann et al. (2002) and Smith and Baltes (1999) for perceived other's control, Passyn and Sujan (2006) and Peloza et al. (2013) for selfaccountability, and Tilghman-Osborne, Cole, Felton, and Ciesla (2008) for characterological self-blame and behavioral self-blame. For CP, respondents rated each statement for the above scales on Likert-scale ranging from 1 to 7 , with 1 indicating strongly disagree and 7 strongly agree. For self-blame, respondents rated each statement for the above scales on Likert-scale ranging from 1 to 7, with 1 indicating does not apply to me at all and 7 applies very well to me. Lastly, for self-accountability and perceived other's control, respondents rated each statement for the above scales on Likert-scale ranging from 1 to 7 , with 1 indicating definitely would not think and 7 definitely would think. Appendix A lists all items and their descriptive statistics under each construct. 
To conduct a confirmatory factor analysis (CFA), partial least squares structural equation modelling (PLS-SEM) was selected. This instrument offers some key advantages. First, PLS is desirable for the initial stages of theory building and adding new construct(s) that previously did not have enough empirical attention (Hair, Hult, Ringle, \& Sarstedt, 2017; Oom do Valle \& Assaker, 2015). Second, PLS provides unbiased model estimation with both non-normal and normal distributional properties (Hair et al. 2014). Z-scores were checked for skewness and kurtosis of each questionnaire item with IBM-SPSS ageist acceptable value between -3 and +3 (Mardia, 1970). Skewness and kurtosis were also tested. The results showed that the assumption of normality was violated. The measurement and structural model were examined within SmartPLS 3.0 software (Ringle, Wende, \& Becker, 2014). The non-parametric bootstrapping procedure was analyzed with 673 cases, 5000 subsamples (Hair et al. 2014).

\section{Phase 5: Replication in other country}

The scale was validated with Chinese data in order to see if tourists in different geographical and cultural context react similarly to items. This would also help assess the generalizability of the CP scale. Data were collected from 418 tourists in Shanghai and Beijing, with 53.1\% of female respondents. Of the sample, $48.1 \%$ were between $36-56$ years of age and above. $60.2 \%$ of the informants had a basic education or had finished high school. The questionnaire was translated into Chinese using a back-translation approach. Harman's one factor was used to test the occurrence of CMV. The eigenvalue PCA identified eight factors, and the highest portion of variance described by one factor was $25.12 \%$. Thus, CMV is not a concern for phase 5 .

\section{Results}

\section{Results of phase 3: Items' purification}

Using IBM-SPSS 22 software, principal component analysis (PCA) was run with promax rotation and no restriction on the number of factors. The sample size of 200 is considered as a fair sample size for PCA (Hair et al., 2010). The KMO measure of sampling competence value was .92 and Bartlett's Test of Sphericity was $560.90(p<.001)$ indicating data is suitable for PCA. The study results indicate that all eight items loaded under one block with Eigen values of higher than 1, which explains $93.14 \%$ of the variance in sample size of 210 . As shown in Table 1, all item loadings were above the minimum threshold with the block $(\geq$ .50) (Hair et al., 2010) and items were correlated, thus we can keep all the items for the CP construct (Nunnally, 1978). Reliability analysis (Cronbach's $\alpha=.80$ ) of the one extracted factor reached above the required threshold of .70. We also tested for multicollinearity among the items using variance inflation factor (VIF). The VIF values were under the thresholds of 5 (Table 1) (Hair et al., 2010).

Table 1. PCA results - Study 3

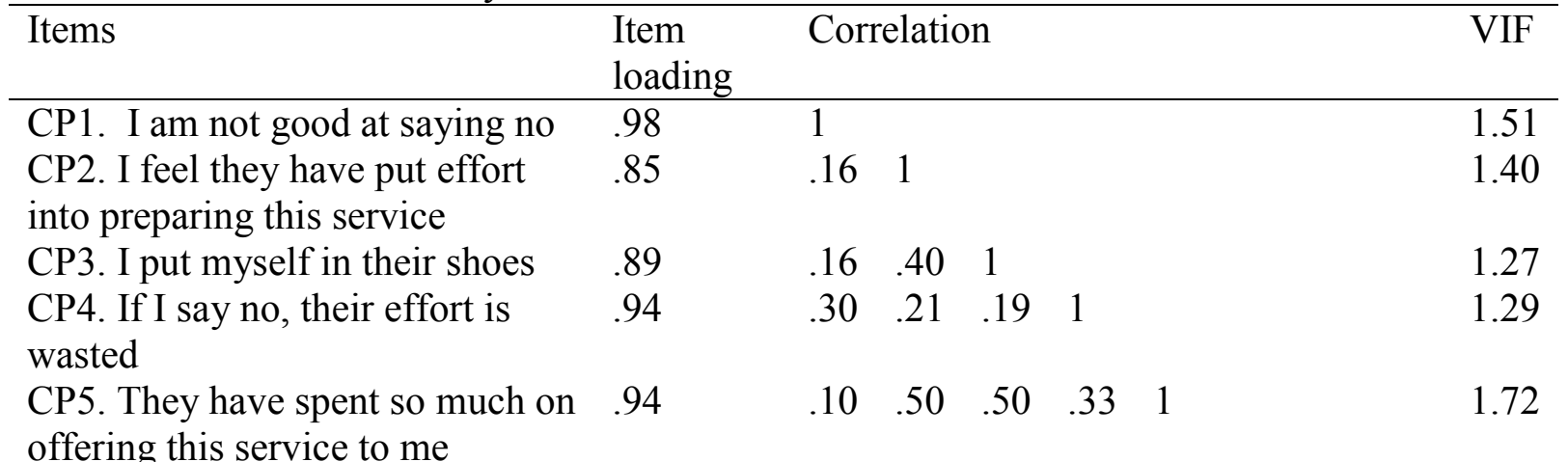


CP6. I will make them happy if I $\quad .82$ accept their offer

CP7. Rejecting their offer is to $\quad .81$

81

$\begin{array}{llllll}.34 & .24 & .25 & .33 & .26 & 1\end{array}$

undermine their skills

CP8. I may enjoy this service

.91

$\begin{array}{lllllll}.31 & .23 & .25 & .30 & .23 & .55 & 1\end{array}$

1.25

Results of phase 4: Analysis of measurement and structural model

The validity and reliability of the reflective measures were tested using composite reliability (CP), Cronbach's Alpha ( $\alpha$ ), factor loadings, and average variance extracted (AVE) to test convergent validity. For all constructs, the factor loadings, composite reliability, and Cronbach's Alpha values should be above the required cut-off point of .70 (Fornell \& Larcker, 1981; Hair et al., 2010). The AVE should exceed the threshold of .50 for all constructs (Hair et al., 2010). Fornell and Larcker's (1981) criterion was used to test discriminant validity, which requires a construct's AVE to be larger than the square of its largest correlation with any construct. Following Henseler, Ringle, and Sarstedt (2015) approach, heterotrait-monotrait ratio of correlations (HTMT) tactic was also used. Henseler et al. (2015) claim that the HTMT approach illustrates greater performance, by means of a Monte Carlo simulation research, than the Fornell-Larcker's criterion approach. If the HTMT value is below .85, discriminant validity must be acknowledged between constructs. In this study, HTMT values of the constructs ranged from .56 to .77. The HTMT inference criterion was also assessed employing complete bootstrapping to check whether HTMT was significantly dissimilar from 1. HTMT inference indicates that all HTMT values were significantly different from 1 (ranging from .64 to .83), thus discriminate validity was established (Wells, Taheri, Gregory-Smith, \& Manika, 2016). Table 2 indicates that the constructs have adequate convergent and discriminate validity.

Finally, following Wanous and Reichers (1999) recommendation, meta-analytic approach was used. A positive correlation was found between single global item and CP items. The external validity was tested to discover if each indicator could be significantly correlated with a 'global item' that recaps the togetherness of the CP measure. Therefore, an additional item was created: 'In my opinion, ceremonious politeness is the action of joining to the comfort and pleasure of others'. Positive associations were found between items and a global CP item (Table 3). Stone-Geisser's $\mathrm{Q}^{2}$ value tested the criterion of predictive relevance (Hair et al., 2017). The $\mathrm{Q}^{2}$ value is gained by using the blindfolding procedure. For this study, cross-validated redundancy procedure was used to assess $\mathrm{Q}^{2} . \mathrm{A}^{2}$ greater than 0 means that the model has predictive relevance. Following Wetzels, Odekerken-Schröder, and van Oppen (2009) recommendation, the Goodness of Fit (GoF) index was also tested. SRMR (standardized root mean square residual) was used as yet another GoF indicator (Henseler et al., 2014). The recommended value for SRMR is less than .08, which demonstrated the predictive validity of CP scale (see Table 2 ).

Following Cohen's (1988) cut-off criteria, the index was measured in contradiction of the GoF criterion for small (.10), medium (.25), and large (.36) effect sizes. Cohen's effect sizes $\left(f^{2}\right)$ were also tested. The rule of thumb is that the significant paths in the inners model should be above .02, which indicates satisfactory effects for the endogenous latent constructs (Henseler, Ringle, \& Sinkovics, 2009). The result showed that the $f^{2}$ values in the inner model were all above .02 . Thus, there are satisfactory effects for latent constructs. The model in the study explains $56 \%$ of CP, $61.2 \%$ of characterological self-blame, and $40 \%$ of the behavioral self-blame, which are all above the recommended value of .10 (Hair et al., 2010). All the statistically significant relationships were in the hypothesized direction, which confirms the nomological validity of CP scale (see Table 4). The control variables (i.e., age, education and gender) had a significant effect on $\mathrm{CP}$, suggesting that age, education, and 
gender play a role on CP (Table 4). Future studies may test these relationships in other contexts. Following Kline's (2011) and Hair et al.'s (2010) recommendation, an invariance test was used to indicate whether a series of items test the same variables among different groups and eventually enhances the validity of the measurement model. A Chi-square statistic was used to evaluate two groups' invariance for age (i.e., young and old participants) and gender (i.e., male and female). The findings demonstrated that the Chi-square among these groups was not significant ( $p=.14$ for age; $p=.23$ for gender), yielding that the measurement model was statistically acceptable.

In addition, analysis of the indirect effects with the bootstrapping method, recommended by Williams and MacKinnon (2008) and Taheri, Farrington, Curran, and O‘Gorman (2017) (Table 5) was employed. A 95\% confidence interval (CI) of the parameter estimates was used based on resampling 5000 times. Consequently, if the direct effect between two construct relationships is significant, the study findings indicate partial mediation. Nevertheless, if the direct effect between respected two constructs is not significant, then the results show full mediation (Lee et al. 2016). Here, self-accountability indirectly impacts on characterological self-blame through CP (CI: .11-.14). In addition, selfaccountability indirectly impacts on behavioral self-blame through CP (CI: .15-.19). Since the direct influences were significant, study results reveal that $\mathrm{CP}$ partially mediates the impact of self-accountability on characterological self-blame and behavioral self-blame. Perceived other's control indirectly affects characterological self-blame through CP (CI: .04-.10). Since the direct influences were significant, the research findings show that $\mathrm{CP}$ partially mediates the impact of perceived other's control on characterological self-blame. Finally, perceived other's control indirectly affects behavioral self-blame through CP (CI: .13-.14). Since the direct influences were significant, study results indicate that CP partially mediates the impact of perceived other's control on behavioral self-blame. These research findings are consistent with previous studies (Bonaccio \& Dalal, 2006; Peloza et al., 2013; Reb \& Connolly, 2010; Theotokis \& Manganari, 2014). 
Table 2. Reliability and validity- study 4 and 5

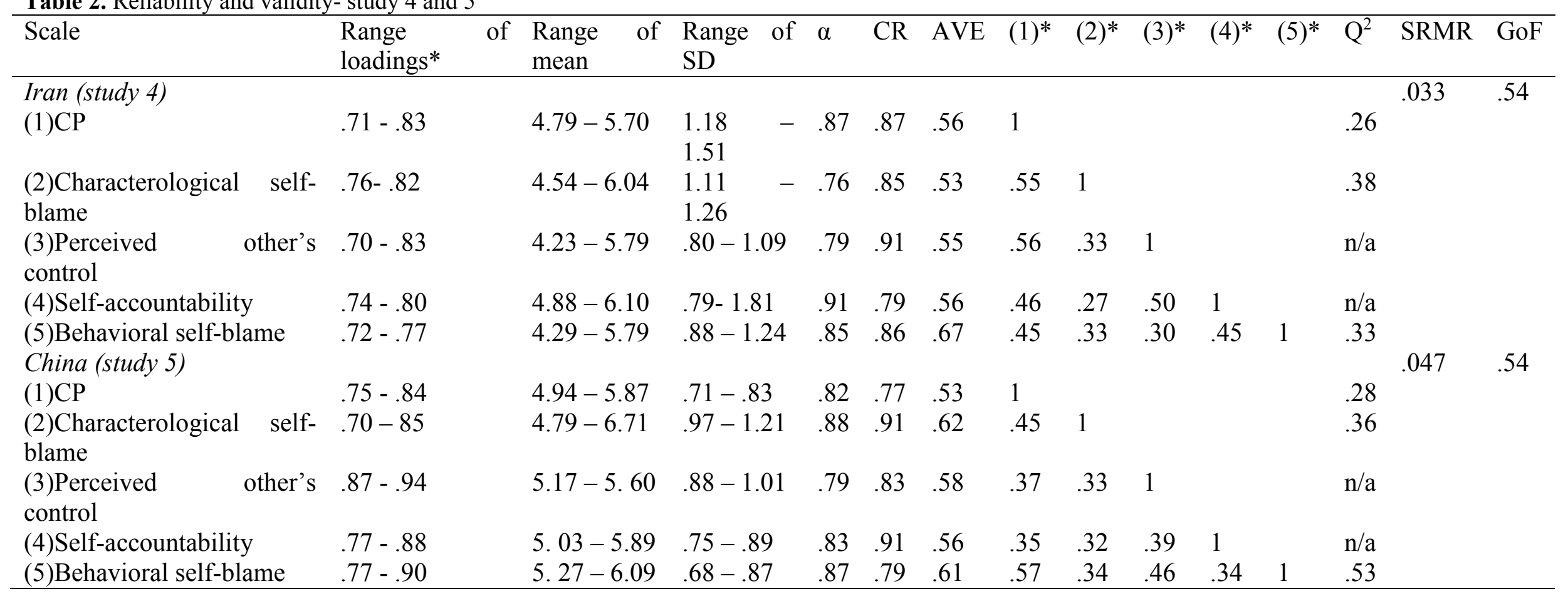


Table 3

Spearman's rank correlation - Study 4 and 5

\begin{tabular}{lll}
\hline Items & \multicolumn{2}{c}{$\begin{array}{c}\text { Spearman's rank } \\
\text { correlation coefficient }\end{array}$} \\
\cline { 2 - 3 } & Iran-Study 4 & China-Study 5 \\
\hline CP1 & $.12^{*}$ & $.12^{*}$ \\
CP2 & $.19^{*}$ & $.26^{*}$ \\
CP3 & $.16^{*}$ & $.17^{*}$ \\
CP4 & $.82^{*}$ & $.72^{*}$ \\
CP5 & $.34^{*}$ & $.78^{*}$ \\
CP6 & $.33^{*}$ & $.42^{*}$ \\
CP7 & $.31^{*}$ & $.37^{*}$ \\
CP8 & $.33^{*}$ & $.38^{*}$ \\
\hline
\end{tabular}

Note: ${ }^{*} p<.05$; N.B. (2-tailed)

Table 4. Estimates of direct paths and control variables - Study 4 and 5

\begin{tabular}{|c|c|c|c|c|}
\hline \multirow[b]{2}{*}{ Direct paths } & \multicolumn{2}{|c|}{ Iran-Study 4} & \multicolumn{2}{|c|}{ China-Study 5} \\
\hline & $\begin{array}{l}\text { Path } \\
\text { coefficient }\end{array}$ & $t$-values & $\begin{array}{l}\text { Path } \\
\text { coefficient }\end{array}$ & $t$-values \\
\hline Self-accountability $\rightarrow$ CP & .46 & 13.01 & .38 & 3.32 \\
\hline Perceived other's control $\rightarrow \mathrm{CP}$ & .37 & 10.14 & .20 & 3.63 \\
\hline $\mathrm{CP} \rightarrow$ Characterological self-blame & .28 & 6.53 & .27 & 4.08 \\
\hline $\mathrm{CP} \rightarrow$ Behavioral self-blame & .38 & 6.91 & .21 & 3.95 \\
\hline Self-accountability $\rightarrow$ Characterological self-blame & .30 & 6.99 & .13 & 5.57 \\
\hline Self-accountability $\rightarrow$ Behavioral self-blame & .08 & 2.01 & .29 & 3.99 \\
\hline $\begin{array}{l}\text { Perceived other's control } \rightarrow \text { Characterological self- } \\
\text { blame }\end{array}$ & .31 & 8.12 & .30 & 4.79 \\
\hline $\begin{array}{l}\text { Perceived other's control } \rightarrow \text { Behavioral self-blame } \\
\text { Control variables }\end{array}$ & .23 & 5.06 & .22 & 3.96 \\
\hline Age $\rightarrow$ Self-accountability & .01 & .68 & .01 & 1.76 \\
\hline Age $\rightarrow$ Perceived other's control & .05 & .97 & .10 & 2.01 \\
\hline Age $\rightarrow \mathrm{CP}$ & .21 & 3.21 & .20 & 3.89 \\
\hline Age $\rightarrow$ Characterological self-blame & .02 & .18 & .07 & .79 \\
\hline Age $\rightarrow$ Behavioral self-blame & .01 & .27 & .02 & .78 \\
\hline Gender $\rightarrow$ Self-accountability & .05 & .89 & .10 & 2.7 \\
\hline Gender $\rightarrow$ Perceived other's control & .04 & .78 & .07 & 1.70 \\
\hline Gender $\rightarrow \mathrm{CP}$ & .18 & 4.23 & .27 & 5.20 \\
\hline Gender $\rightarrow$ Characterological self-blame & .07 & .79 & .06 & .56 \\
\hline Gender $\rightarrow$ Behavioral self-blame & .06 & .78 & .07 & .89 \\
\hline Education $\rightarrow$ Perceived other's control & .05 & .90 & .10 & 3.03 \\
\hline Education $\rightarrow \mathrm{CP}$ & .28 & 4.23 & .30 & 7.09 \\
\hline Education $\rightarrow$ Characterological self-blame & .09 & 1.20 & .20 & 4.09 \\
\hline Education $\rightarrow$ Behavioral self-blame & .06 & .78 & .09 & 1.88 \\
\hline Education $\rightarrow$ Perceived other's control & .08 & 1.00 & .20 & 3.89 \\
\hline
\end{tabular}

Notes: $t$-values for the item loadings to two-tailed test: $t>1.96$ at $p<.05, t>2.57$ at $p<.01, t>3.29$ at $p<.001$. 
Table 5. Estimates of indirect paths - Study 4 and 5

\begin{tabular}{|c|c|c|c|c|c|c|c|c|}
\hline \multirow[t]{2}{*}{ Indirect paths } & \multicolumn{4}{|c|}{ Iran-Study 4} & \multicolumn{4}{|c|}{ China-Study 5} \\
\hline & $\begin{array}{l}\text { Indirect } \\
\text { effect }\end{array}$ & $\begin{array}{l}t \text { - } \\
\text { values }\end{array}$ & $\begin{array}{l}\text { Low } \\
\text { CI }\end{array}$ & $\begin{array}{l}\text { High } \\
\text { CI }\end{array}$ & $\begin{array}{l}\text { Indirect } \\
\text { effect }\end{array}$ & $\begin{array}{l}t \text { - } \\
\text { values }\end{array}$ & $\begin{array}{l}\text { Low } \\
\text { CI }\end{array}$ & $\begin{array}{l}\text { High } \\
\text { CI }\end{array}$ \\
\hline Self-accountability & .13 & 5.90 & .11 & .14 & .17 & 8.09 & .13 & .18 \\
\hline Characterological self-blame & & & & & & & & \\
\hline $\begin{array}{l}\text { Self-accountability } \rightarrow \text { CP } \rightarrow \\
\text { Behavioral self-blame }\end{array}$ & .18 & 5.83 & .15 & .19 & .10 & 3.89 & .08 & .12 \\
\hline $\begin{array}{l}\text { Perceived other's control } \rightarrow \mathrm{CP} \\
\rightarrow \text { Characterological self-blame }\end{array}$ & .10 & 5.73 & .04 & .10 & .12 & 6.00 & .10 & .15 \\
\hline $\begin{array}{l}\text { Perceived other's control } \rightarrow \text { CP } \\
\rightarrow \text { Behavioral self-blame }\end{array}$ & .14 & 5.30 & .13 & .15 & .16 & 5.89 & .14 & .18 \\
\hline
\end{tabular}

Notes: $t$-values for the item loadings to two-tailed test: $t>1.96$ at $p<.05, t>2.57$ at $p<.01, t>3.29$ at $p<.001$.

\section{Results of phase 5: Analysis of measurement and structural model}

The same reliability and validity procedures used in phase 4 were employed. Using PLSSEM, Table 2 and 3 indicate reliability and validity for study 5. Table 2 also indicates the predictive relevance of phase 5. The GoF value is .515 . Cohen's effect sizes $\left(f^{2}\right)$ were above the threshold. The SRMR value is .06. HTMT values of the scales ranged from .51 to .70. HTMT $_{\text {inference }}$ showed that all HTMT values were significantly different from 1 (ranging from .62 to .71). Therefore, discriminate validity was established. The model explains $43.3 \%$ of CP, $59.7 \%$ of characterological self-blame, and $49.6 \%$ of the behavioral self-blame. Appendix A shows the descriptive statistics for the China data.

As presented in Table 4, the study results of the analysis provide empirical support for all of the hypotheses for the Chinese data. Moreover, the analysis of the indirect effects with the bootstrapping method, recommended by Williams and MacKinnon (2008) and Taheri et al. (2017) (Table 5) was used. Self-accountability indirectly influences characterological self-blame through $\mathrm{CP}$ (CI: .13-.18). In addition, self-accountability indirectly impacts behavioral self-blame through CP (CI: .08-.12). Since the direct influences were significant, the study results reveal that $\mathrm{CP}$ partially mediates the influence of selfaccountability on characterological self-blame and behavioral self-blame. Perceived other's control indirectly affects characterological self-blame through CP (CI: .10-.15). Since the direct impacts were significant, the research findings show that $\mathrm{CP}$ partially mediates the impact of perceived other's control on characterological self-blame. Finally, perceived other's control indirectly affects behavioral self-blame through CP (CI: .14-.18). Since the direct influences were significant, the study results indicate that $\mathrm{CP}$ partially mediates the impact of perceived other's control on behavioral self-blame. These results are consistent with previous studies (Bonaccio \& Dalal, 2006; Peloza et al., 2013; Reb \& Connolly, 2010; Theotokis \& Manganari, 2014). Thus, phase 5 provides further evidence of the convergent, discriminant, and predictive validity of the new $\mathrm{CP}$ scale and its cross-cultural equivalence.

\section{General Discussion}

This study examines the impact of personal and social attributes on CP in social interaction when guests receive service and food from a host (such as an eating situation), where VFR tourists encounter a sense of self-blame. Based on a rigorous scale-development process, the research confirmed the validity and reliability of $\mathrm{CP}$ as a reflective scale in five successive studies. As the CP scale has been validated to be a general scale across geographically and culturally different populations (i.e., British and international students [from 12 different nationalities], Iranian and Chinese tourists' samples), it can therefore be used as a research tool in future research studies to evaluate the role of CP in VFR tourism. To further evaluate the predictive validity of the $\mathrm{CP}$ scale, the association between the $\mathrm{CP}$, antecedents, and outcomes variables were used using attribution and blame theories (Calder \& Burnkrant, 
1977; Shaver \& Drown, 1986). The theoretical and practical implications of the findings of this study can be extended to several areas in tourism and hospitality research.

The study makes four important theoretical contributions. First, while previous research has focused largely on external factors (e.g., food quality, quantity, and diversity) to understand tourists' experiences with food consumption (e.g., Chang, Kivela, \& Mak, 2011; Kim \& Eves, 2012; Mynttinen, Logrén, Särkkä-Tirkkonen, \& Rautiainen, 2015; Okumus, Okumus, \& McKercher, 2007; Organ, Koenig-Lewis, Palmer, \& Probert, 2015; Quan \& Wang, 2004), this study examines the phenomenon in relation to their own personal attributes. This study further extends Koc's (2013) work toward furthering our understanding of tourists' undesirable experiences with food consumption. Specifically, it identifies selfaccountability and perceived others' control as two personal attributes that effect tourists' eating behavior while visiting friends and relatives, and eventually their sense of self. This study argues that, apart from external factors (e.g., food) and conditions (e.g., of commercial settings), tourists' personal attributes - that have remained less explored in tourism research play a significant role in determining their overall travel experience and their sense of self.

Second, this study introduces the concept of CP into the literature and explains the reasons why, under certain conditions, individuals feel obliged to behave in certain ways (e.g., overeating) that yield negative consequences (e.g., self-blame) for them. This development emerged from the analysis of tourists' dietary behavior in the non-commercial context of the home that had remained overlooked by previous research (e.g., Hillel et al. 2013; Getz et al. 2014; Koc 2013; Mynttinen et al. 2015). These findings demonstrate that CP can significantly influence tourists' eating behavior, sense of self, and their overall travel experiences.

Third, the concept of CP into business research in general and services research in particular was introduced. This study explains the reasons why, under certain conditions, individuals may feel obliged to behave in certain ways (e.g., overeating) that yield negative consequences (e.g., self-blame) for them. Viewed from a services perspective (Vargo \& Lusch, 2004), hospitality is a service context in which the host and the guest follow certain protocols (formal/informal) to co-create sociality, or what Cova (1997) calls the linking value of communal consumption situations. This study suggests that $\mathrm{CP}$ has the theoretical power to explain why, under certain conditions, individuals may compromise certain aspects of their self-standards and behavior in order to please others.

Forth, for the first time in VFR tourism research, this study develops and validates a $\mathrm{CP}$ scale to measure its impact on tourists' behavior and self-perception. The importance of the CP scale is that it can be adopted and adapted in different empirical settings in the tourism context for understanding tourists' behaviors and identifying the potential causes of their dissatisfaction with diverse phenomena, especially in situations where certain sociocultural norms (e.g., politeness and social interactions) can influence their perceptions of self/others' control and overall tourism experience.

This study also offers a number of practical implications. A key research finding is that tourists' high perceived others' control prompts them to behave against their selfstandards and, consequently, feel negative for their loss of self-control. This implies that practitioners in different sectors of the tourism industry need to focus on tourists' perception of self. In other words, although resources (e.g., human such as hosts, or non-human such as food) and facilities (e.g., physical evidence) may significantly enhance the tourism experiences, what should matter the most is whether or not, and the extent to which, such arrangements positively contribute to the tourists' sense of self. This may be achieved by creating environments in which tourists can feel more in control of themselves and their actions. 
Relevant to this is the potential impact of CP on the tourism economy. Since VFR avails tourists with alternative means of accommodation, eating, and reducing travel expenses (Dekimpe et al., 2016), the negative feelings that arise because of CP may influences their decision on staying with friends and relatives and consume food offered by them.

Another important finding is that, through the mediating role of $\mathrm{CP}$, tourists' high self-accountability negatively influences their social interaction and overall travel experiences. This finding implies that there is a need for balancing their level of selfaccountability. This is not an easy task as people's sense of self-accountability varies between individuals. Yet, to some extent, creating such balance may be realized through education and communication. For example, tourism offices and tour operators can clarify and communicate the rights and responsibilities of tourists and service providers in order to manage expectations and optimize tourists' experiences. Specifically, in cross-cultural contexts, where tourists and service providers do not perform the same level of CP, training and education of both tourists and service providers can help.

The research findings also show the explanatory power of CP for understanding some of the discrepancies between tourists' beliefs and actions. This indicates that by understanding the complexities of $\mathrm{CP}$, managers can understand, predict, and even manage tourists' behaviors and expectations. For example, given the rise of commercial, home-based accommodation (Di Domenico \& Lynch 2007; Hassanli, Gross, \& Brown 2016), business owners' familiarity with $\mathrm{CP}$ and their subsequent strategies (e.g., reciprocal verbal and behavioral politeness) can enhance visitors' overall experience, especially if visitors come from certain sociocultural backgrounds that widely exercise CP. Additionally, since CP may involve incongruence between one's will and action, managers should endeavor to explore the real causes of tourists' dissatisfaction when it arises. For example, out of CP, unhappy customers may verbally express their satisfaction with a hotel's service quality, but either never repeat the custom or generate negative word-of-mouth about that hotel after their visit. A useful way to explore such discrepancies could be to adapt and apply the CP scale to customer satisfaction surveys.

\section{Conclusions and Future Research}

This study aimed to develop and validate a new scale to measure the $\mathrm{CP}$ of tourists, particularly when consuming food in VFR tourism, and establish its value in defining, predicting, and understanding social interaction when guest receives services such food from host in the VFR tourism. With the global acceleration of human mobility (e.g., migration and sojourning), travelling for VFR is also on the rise. VFR entails various activities such as staying at friends or relatives' homes and using tourism to connect with loved ones. Despite its significant contributions to national and international economies (particularly in the services sector), VFR has remained largely undertheorized. In particular, we still lack an indepth understanding of the dynamics of social interactions between hosts and guests in the VFR context. Addressing this gap, the present study introduced the notion of CP into the social science literature, in general, and tourism literature, in particular. Using food consumption as a context, this study demonstrates that CP influences tourists' experiences. Given the complicated nature of interactions between service providers and service receivers in different contexts, this study proposes the concept of $\mathrm{CP}$ and suggests that its construct should be examined in different spaces and conditions in service industries. For example, the CP scale developed in this study can be tested and revised in commercial hospitality settings such as restaurants, cafes, hotels, and so forth.

Similar to any other research, this study has a number of limitations that warrant further research. First, although this study uses a rigorous scale-development process to validate the CP scale in VFR tourism, cross-validation from several countries in different 
continents is needed. Therefore, multi-setting and multi-nation studies are likely to have vital payoffs. Future studies should test a holistic understanding of CP by employing longitudinal designs (qualitative and quantitative) in VFR tourism content. This will also establish the external validity of the construct. Second, this study did not explore the respondents' strategies of coping with or resolving the negative consequences of self-blame related to overeating. Future research should empirically examine these strategies. For example, do these individuals travel less? Do they shorten the duration of their stay? Do they choose alternative accommodations? Or do they follow a strict diet after their travel? Third, it is possible that the effects of $\mathrm{CP}$ and self-blame are moderated by contextual variables (e.g., health literacy). Also, it is worthwhile to investigate the antecedents of $\mathrm{CP}$ in regard to personal characteristics and perceptions. 
Appendix A. Items and descriptive statistics

\begin{tabular}{|c|c|c|c|c|}
\hline Item & Mean & Std. Deviation & Skewness & Kurtosis \\
\hline \multicolumn{5}{|l|}{ Iran Data } \\
\hline \multicolumn{5}{|l|}{ Ceremonious Politeness $(\mathrm{CP})$} \\
\hline 1 I am not good at saying no & 5.70 & 1.539 & -1.089 & .489 \\
\hline 2 They have put so much effort into preparing this food & 5.32 & 1.700 & -.869 & -.085 \\
\hline 3 I put myself in their shoes & 5.12 & 1.904 & -.758 & -.591 \\
\hline 4 If I do not say no, their effort for food is wasted & 3.88 & 2.167 & .052 & -1.371 \\
\hline 5 They have spent so much on offering this food & 3.67 & 1.958 & .121 & -1.121 \\
\hline 6 I will make them happy if I accept eating the food & 4.15 & 1.988 & -.085 & -1.199 \\
\hline $\begin{array}{l}7 \text { Rejecting their eating offer is to undermine their } \\
\text { cooking skills }\end{array}$ & 3.79 & 1.908 & -.012 & -1.073 \\
\hline 8 I may enjoy this food & 4.05 & 2.014 & -.054 & -1.164 \\
\hline \multicolumn{5}{|l|}{ Perceived other's control } \\
\hline $\begin{array}{l}9 \text { The good things in my life are determined by other } \\
\text { people }\end{array}$ & 5.79 & 1.610 & -3.339 & 1.059 \\
\hline $\begin{array}{l}10 \text { Other people generally make sure that nothing goes } \\
\text { wrong in my life }\end{array}$ & 5.67 & 1.504 & -3.156 & .807 \\
\hline $\begin{array}{l}11 \text { Other people generally arrange for good things to } \\
\text { happen in my life }\end{array}$ & 5.29 & 2.528 & 3.159 & 1.203 \\
\hline $\begin{array}{l}12 \text { I depend on others to ensure that there are no } \\
\text { problems in my life }\end{array}$ & 3.23 & 1.782 & .258 & -.905 \\
\hline \multicolumn{5}{|l|}{ Self-accountability } \\
\hline $\begin{array}{l}13 \text { How accountable are you to behave in eating } \\
\text { situation in a party? }\end{array}$ & 3.88 & 1.791 & .658 & -.594 \\
\hline $\begin{array}{l}14 \text { How strongly are you motivated to live up to your } \\
\text { manner? }\end{array}$ & 3.23 & 1.813 & .330 & -.950 \\
\hline $\begin{array}{l}15 \text { How accountable do you feel to your own self- } \\
\text { standard? }\end{array}$ & 4.76 & 1.810 & -.530 & -.609 \\
\hline \multicolumn{5}{|l|}{ Characterological self-blame } \\
\hline 16 Why do I always get into overeating situation? & 3.54 & 2.238 & .292 & -1.373 \\
\hline 17 I know this will happen to me again & 4.04 & 2.114 & -.041 & -3.315 \\
\hline $\begin{array}{l}18 \text { This happened to me in this party because it happens } \\
\text { in all my parties }\end{array}$ & 3.71 & 2.194 & .214 & -3.362 \\
\hline $\begin{array}{l}19 \text { This happens because I am not very good in stop } \\
\text { eating }\end{array}$ & 3.83 & 2.265 & .109 & -1.474 \\
\hline $\begin{array}{l}20 \text { If I were a smarter in my eating, I would not have } \\
\text { overeating problem in the party }\end{array}$ & 3.70 & 2.247 & .213 & -3.422 \\
\hline \multicolumn{5}{|l|}{ Behavioural self-blame } \\
\hline 21 I should try harder to avoid overeating situation & 3.29 & 2.107 & .419 & -1.133 \\
\hline 22 I should have tried harder about my eating! & 3.68 & 2.240 & .211 & -1.417 \\
\hline 23 How can I keep this from happening to me again? & 4.10 & 2.304 & -.067 & -1.417 \\
\hline $\begin{array}{l}24 \text { I should have reacted differently when I got to the } \\
\text { eating stage in the party }\end{array}$ & 3.73 & 2.314 & .169 & -1.491 \\
\hline 25 I should have asked the host to let me stop eating & 3.84 & 2.081 & .797 & -.739 \\
\hline $\begin{array}{l}26 \text { I should have asked the host to let me the part I } \\
\text { cannot eat home with me }\end{array}$ & 3.56 & 2.282 & .281 & -3.412 \\
\hline
\end{tabular}

\section{China Data}

Ceremonious Politeness (CP)

$1 \mathrm{I}$ am not good at saying no

$5.04 \quad 1.762$

$-.662$

$-.497$

1 I am not good at saying no

4.94

1.726

$-.536$

$-.534$

2 They have put so much effort into preparing this food

5.45

1.708

$-.970$

.113

3 I put myself in their shoes

$5.06 \quad 1.791$

$-.632$

$-.562$

4 If I do not say no, their effort for food is wasted

4.87

1.688

$-.589$

$-.378$ 
5 They have spent so much on offering this food to me 6 I will make them happy if I accept eating the food

7 Rejecting their eating offer is to undermine cooking their skills

Perceived other's control

9 The good things in my life are determined by other people

10 Other people generally make sure that nothing goes wrong in my life

11 Other people generally arrange for good things to happen in my life

12 I depend on others to ensure that there are no problems in my life

Self-accountability

13 How accountable are you to behave in eating situation in a party?

14 How strongly are you motivated to live up to your manner?

15 How accountable do you feel to your own self-

standard?

Characterological self-blame

16 Why do I always get into overeating situation?

17 I know this will happen to me again

18 This happened to me in this party because it happens in all my parties

19 This happens because I am not very good in stop eating

20 If I were a smarter in my eating, I would not have overeating problem in the party

Behavioural self-blame

21 I should try harder to avoid overeating situation

22 I should have tried harder about my eating!

23 How can I keep this from happening to me again?

24 I should have reacted differently when I got to the eating stage in the party

25 I should have asked the host to let me stop eating

26 I should have asked the host to let me the part I

cannot eat home with me

\begin{tabular}{|c|c|c|c|}
\hline 5.15 & 1.716 & -.728 & -.341 \\
\hline 4.69 & 1.918 & -.462 & -.902 \\
\hline 4.86 & 1.831 & -.557 & -.739 \\
\hline 3.34 & 2.014 & 1.370 & -3.140 \\
\hline 3.33 & 1.965 & .389 & -1.079 \\
\hline 3.28 & 1.989 & .437 & -3.079 \\
\hline 3.40 & 1.989 & .477 & -2.031 \\
\hline 4.84 & 1.781 & -.623 & -.398 \\
\hline 4.88 & 1.635 & -.746 & .031 \\
\hline 4.69 & 1.708 & -.553 & -.398 \\
\hline 4.19 & 1.957 & -.121 & -1.228 \\
\hline 4.09 & 1.955 & -.082 & -1.104 \\
\hline 3.97 & 1.937 & -.004 & -2.086 \\
\hline 4.27 & 2.039 & -.174 & -3.238 \\
\hline 4.61 & 1.938 & -.411 & -.943 \\
\hline 4.15 & 1.988 & -.164 & -1.116 \\
\hline 4.17 & 2.004 & -.170 & -2.213 \\
\hline 5.00 & 1.964 & -.631 & -.783 \\
\hline 4.84 & 1.753 & -.435 & -.742 \\
\hline 5.10 & 1.681 & -.611 & -.500 \\
\hline 5.116 & 1.661 & -.642 & -3.393 \\
\hline
\end{tabular}

$\begin{array}{llll}4.69 & 1.918 & -.462 & -.902\end{array}$

$\begin{array}{llll}4.86 & 1.831 & -.557 & -.739\end{array}$

$\begin{array}{llll}3.34 & 2.014 & 1.370 & -3.140\end{array}$

$\begin{array}{llll}3.33 & 1.965 & .389 & -1.079\end{array}$

$\begin{array}{llll}3.28 & 1.989 & .437 & -3.079\end{array}$

$\begin{array}{llll}3.40 & 1.989 & .477 & -2.031\end{array}$ 


\section{References}

Ambady, N., Koo, J., Lee, F., \& Rosenthal, R. (1996). More than words: Linguistic and nonlinguistic politeness in two cultures. Journal of Personality and Social Psychology, 70, 996-1011.

Aramberri, J. (2001). THE HOST SHOULD GET LOST: Paradigms in the Tourism Theory. Annals of Tourism Research, 28(3), 736-761.

Asiedu, A. B. (2008). Participants' characteristics and economic benefits of visiting friends and relatives (VFR) tourism-An international survey of the literature with implications for Ghana. International Journal of Tourism Research, 10(6), 609-621.

Azadarmaki, T., \& Bikaran-Behesht, M. (2010). Taarof dar ziste roozmarreye Irani. Barg-e Farhang, 22, 196-209.

Backer, E. (2012). VFR travel: It is underestimated. Tourism Management, 33(1), 74-79.

Belk, R., Painter, J., \& Semenik, R. (1981). Perferred solutions to the energy crisis as a function of causal attributions. Journal of Consumer Research, 8(December), 306312.

Bonaccio, S., \& Dalal, R. S. (2006). Advice taking and decision-making: An integrative literature review, and implications for the organizational sciences. Organizational Behavior \& Human Decision Processes, 101, 127-151.

Boyatzis, R. E. (1998). Transforming Qualitative Information: Thematic Analysis and Code Development London: Sage.

Calder, B. J., \& Burnkrant, R. E. (1977). Interpersonal influnces on consumer behaviour: An attribution theory approach Journal of Consumer Research, 4(June), 29-38.

Chang, R. C. Y., Kivela, J., \& Mak, A. H. N. (2011). Attributes that influence the evaluation of travel dining experience: When East meets West. Tourism Management, 32, 307316.

Cohen, E. (1979). A Phenomenology of Tourist Types. Sociology, 13, 179-201.

Cohen, J. (1988). Statistical Power Analysis for the Behavioral Sciences (Second ed.). Hillsdale, NJ: Lawrence Erlbaum Associates.

Cova, B. (1997). Community and consumption: Towards a definition of the linking value of products or services. European Journal of Marketing, 31(3/4), 297-316.

DeVellis, F. R. (2003). Scale Development: Theory and Applications (Second ed.). USA: Sage Publications.

Fetscherin, M., \& Stephano, R.-M. (2016). The medical tourism index: Scale development and validation. Tourism Management, 52, 539-556.

Goffman, E. (1959). The Presentation of Self in Everyday Life. New York: Doubleday: Garden City.

Hair, J. F. J., Black, W. C., Babin, B. J., \& Anderson, R. E. (2010). Multivariate Data Analysis: A Global Perspective (7th ed.). USA: Pearson.

Hair, J. F. J., Hult, G. T. M., Ringle, C. M., \& Sarstedt, M. (2017). A primer on Partial Least Squares Structural Equation Modeling (PLS-SEM) (2nd ed.). Los Angeles, CA: Sage.

Harman, H. H. (1967). Modern factor analysis. Chicago: University of Chicago Press.

Heider, F. (1958). The psychology of interpersonal relations. New York: Wiley.

Henseler, J., Dijkstra, T. K., Sarstedt, M., Ringle, C. M., Diamantopoulos, A., Straub, D. W., ... Calantone, R. (2014). Common beliefs and reality about PLS comments on Rönkkö and Evermann (2013). Organizational Research Methods, 17(2), 182-209.

Henseler, J., Ringle, C. M., \& Sarstedt, M. (2015). A New Criterion for Assessing Discriminant Validity in Variance-based Structural Equation Modeling. Journal of the Academy of Marketing Science, 43(1), 115-135. 
Henseler, J., Ringle, C. M., \& Sinkovics, R. R. (2009). The use of partial least squares path modeling in international marketing. Advances in International Marketing, 20, 277319.

Jafari, A., Taheri, B., \& vom Lehn, D. (2013). Cultural consumption, interactive sociality, and the museum. Journal of Marketing Management, 29(15-16), 1729-1752.

Janoff-Bulman, R. (1979). Characterological versus behavioural self-blame: inquiries into depression and rape. Journal of Personality and Social Psychology, 37, 1798-1809.

Jayaratne, M., Sullivan Mort, G., \& Clare, D. (2015). Sustainability Living in a CarbonPriced Economy: "Shoulds" and "Woulds," Making Amends and Sustainability Guilt. Journal of Nonprofit \& Public Sector Marketing, 27, 1049-5142.

Kerbrat-Orecchioni, C. (2012). Politeness variations and constants in France, from the classic age to today'. In M. Bax \& D. Z. Kádár (Eds.), Understanding Historical (Im)Politeness: Relational linguistic practice over time and across cultures (pp. 131153). Amsterdam: John Benjamins Publishing.

Kim, Y. G., \& Eves, A. (2012). Construction and validation of a scale to measure tourist motivation to consume local food. Tourism Management, 33, 1458-1467.

Kline, R. B. (2011). Principles and practice of structural equation modeling (3rd ed.). New York, NY: The Guilford Press.

Kunzmann, U., Little, T., \& Smith, J. (2002). Perceiving Control: A Double-Edged Sword. Journal of Gerontology: Psychological sciences, 57(6), 484-491.

Larsen, J., Urry, J., \& Axhausen, K. W. (2007). Networks and tourism: mobile social life. Annals of Tourism Research, 34(1), 244-262.

Lee, C., Hallak, R., \& Sardeshmukh, S. R. (2016). Innovation, entrepreneurship, and restaurant performance: A higher-order structural model. Tourism Management, 53, 215-228.

Leech, G. (2005). Politeness: Is there an East-West Divide? . Journal of Foreign Languages, $6(1), 1-130$.

Mardia, K. V. (1970). Measures of multivariate skewness and kurtosis with applications. Biometrika, 57, 519-530.

Michel, J. W., Tews, M. J., \& Kavanagh, M. J. (2014). Development and validation of the Customer-Centered Behavior measure. The Service Industries Journal, 34(13), 10751091.

Miller, G. (2001). The development of indicators for sustainable tourism: results of a Delphi survey of tourism researchers Tourism Management, 22, 351-362.

Mynttinen, S., Logrén, J., Särkkä-Tirkkonen, M., \& Rautiainen, T. (2015). Perceptions of food and its locality among Russian tourists in the South Savo region of Finland. Tourism Management, 48, 455-466.

Nunnally, J. C. (1978). Psychometric Theory. New York: McGraw-Hill.

Okumus, B., Okumus, F., \& McKercher, B. (2007). Incorporating local and international cuisines in the marketing of tourism destinations: The cases of Hong Kong and Turkey. Tourism Management, 28, 253-261.

Oom do Valle, P., \& Assaker, G. (2015). Using Partial Least Squares Structural Equation Modeling in Tourism Research: A Review of Past Research and Recommendations for Future Applications. Journal of Travel Research, 1-14. doi: $0.1177 / 0047287515569779$

Organ, K., Koenig-Lewis, N., Palmer, A., \& Probert, J. (2015). Festivals as agents for behaviour change: A study of food festival engagement and subsequent food choices. Tourism Management, 48, 84-99.

Paci, E. (1994). The major international VFR markets. EIU Travel and Tourism Analyst, 6(1), $36-50$. 
Pan, Y., \& Kádár, D. Z. (2011). Politeness in Historical and Contemporary Chinese. London: Bloomsbury Academic.

Passyn, K., \& Sujan, M. (2006). Self-accountability emotions and fear appeals: Motivating Behavior. Journal of Consumer Research, 32(March), 583-589.

Passyn, K., \& Sujan, M. (2012). Skill-based versus effort-based task difficulty: A taskanalysis approach to the role of specific emotions in motivating difficult actions. Journal of Consumer Psychology, 22, 461-468.

Peloza, J., White, K., \& Shang, J. (2013). Good and Guilt-Free: The Role of SelfAccountability in Influencing Preferences for Products with Ethical Attributes. Journal of Marketing, 77(104-119).

Pinto, D. (2011). Are Americans insincere? Interactional style and politeness in everyday America. Journal of Politeness Research.Language, Behaviour, Culture, 7, 215-238.

Podsakoff, P. M., MacKenzie, S. M., Lee, J., \& Podsakoff, N. P. (2003). Common method variance in behavioral research: a critical review of the literature and recommended remedies. Journal of Applied Psychology, 88(5), 879-903.

Quan, S., \& Wang, N. (2004). Towards a structural model of the tourist experience: an illustration from food experiences in tourism. Tourism Management, 25, 297-305.

Reb, J., \& Connolly, T. (2010). The effects of action, normality, and decision carefulness on anticipated regret: Evidence for a broad mediating role of decision justifiability. Cognition \& Emotion (1-16).

Ringle, C. M., Wende, S., \& Becker, J.-M. (2014). SmartPLS 3.0. from http://www.smartpls.com/

Rossiter, J. R. (2002). The C-OAR-SE procedure for scale development in marketing. International Journal of Research in Marketing, 19(4), 305-335.

Shani, A. (2013). The VFR experience: 'home' away from home? Current Issues in Tourism, $16(1), 1-15$.

Shani, A., \& Uriely, N. (2012). VFR tourism: The host experience. Annals of Tourism Research, 39(1), 421-440.

Shaver, K. G., \& Drown, D. (1986). On causality, responsibility, and self-blame: a theoretical note. Journal of Personality and Social Psychology, 50(4), 697-702.

Smith, J., \& Baltes, P. B. (1999). Profiles of psychological functioning in the old and oldest old. Psychology and Aging, 12, 458-472.

Smith, V. (1978). Hosts and Guests. Oxford: Blackwells.

Spencer-Oatey, H. (2005). (Im) politeness, face and perceptions of rapport: unpackaging their bases and interrelationships. Journal of Politeness Research Language, Behaviour, Culture, 1(1), 95-119.

Taheri, B., Farrington, T., Curran, R., \& O`Gorman, K. (2017). Sustainability and the authentic experience. Harnessing brand heritage - a study from Japan. Journal of Sustainable Tourism. doi: 10.1080/09669582.2017.1310867

Taussig, G. (2002). Coleridge and the Idea of Friendship, 1789-1804. Newark: University of Delaware Press.

Teddlie, C., \& Tashakkori, A. (2009). Foundations of Mixed Methods Research. London: Sage.

Theotokis, A., \& Manganari, E. (2014). The Impact of Choice Architecture on Sustainable Consumer Behavior: The Role of Guilt. Journal of Business Ethics, July, 1-15.

Tilghman-Osborne, C., Cole, D. A., Felton, J. W., \& Ciesla, J. A. (2008). Relation of Guilt, Shame, Behavioral and Characterological Self-Blame to Depressive Symptoms in Adolescents Over Time. Journal of Social and Clinical Psychology, 27(8), 809-842.

Uriely, N. (2010). 'Home' and 'away' in VFR tourism. Annals of Tourism Research, 37(3), 857-860. 
Vargo, S. L., \& Lusch, R. F. (2004). Evolving to a new dominant logic for marketing. Journal of Marketing, 68(January), 1-17.

Wanous, J. P., \& Reichers, A. E. (1999). Overall job satisfaction: how good are single-item measures? Journal of Applied Psychology, 82(2), 247-252.

Wells, V. K., Taheri, B., Gregory-Smith, D., \& Manika, D. (2016). The role of generativity and attitudes on employees home and workplace water and energy saving behaviours. Tourism Management, 56, 63-74.

Wetzels, M., Odekerken-Schröder, G., \& van Oppen, C. (2009). Using PLS path modeling for assessing hierarchical construct models: guidelines and empirical illustration. MIS Quarterly, 33(1), 177-195.

Williams, A., \& MacKinnon, D. P. (2008). Resampling and distribution of the product methods for testing indirect effects in complex models. Structural Equation Modeling, 15(1), 23-51. 